\title{
Experimental and theoretical investigation of composite truss beams
}

\author{
Jan Bujnak ${ }^{1, *}$, Peter Michalek ${ }^{1}$, and Wieslaw Baran ${ }^{2}$ \\ ${ }^{1}$ University of Žilina, Faculty of Civil Engineering, Univerzitná 1, 01026 Žilina, Slovakia \\ ${ }^{2}$ Opole University of Technology, Faculty of Civil Engineering \& Architecture, Katowicka 48, \\ 45-061 Opole, Poland
}

\begin{abstract}
The design specifications of composite trusses are only partially included in the European standards. However this construction system can be considered as one of the most economical for building and bridge structures. To create an interaction between steel and concrete, it is necessary to prevent the relative slip at the steel and concrete interface using the shear connectors. But the local effects of a concentrated longitudinal shear force between steel truss chord and concrete slab, as special task, should be appropriately examined. The finite element analyses can be used to investigate numerically this structural system behaviour, exploiting several computer procedures. The experimental research has tested these procedures. The outputs of this study are presented in the paper.
\end{abstract}

\section{Introduction}

Classical composite structures consist of steel girders, a concrete slab and connectors, whose function is to provide the interaction between slab and girder. Particularly composite steelconcrete trusses can be considered as one of the most economical systems for building, especially for greater spans allowing better use of internal space without restricting columns, as it can be seen in Figure 1a. The trusses are appropriate also to meet the requirements for building height limitation as well as the need to run complex electrical, heating, ventilating, and communication systems. Also composite steel bridges represented in Figure 1b, whose deck is supported on a filigree steel truss structure and slim piers, are particularly preferable especially to conventional concrete bridges.

In the paper, a method of determining the more exact behaviour in steel-concrete beam structures with flexible connectors is presented. To create an interaction between steel parts and concrete, it is necessary to prevent the relative slip at the steel-concrete interface using shear connectors. But the local effects of a concentrated longitudinal force and the distribution of the shear force between steel section and concrete slab, as special task, should be appropriately examined. There is no particular recommendation for the design of composite truss, except the formulas in EN 1994-1-1 [1], clause 6.6.2.3 for the local effect

\footnotetext{
* Corresponding author: jan.bujnak@,fstav.uniza.sk
} 
of a concentrated longitudinal force and the distribution of the longitudinal shear force into local shear flow between steel section and concrete slab.

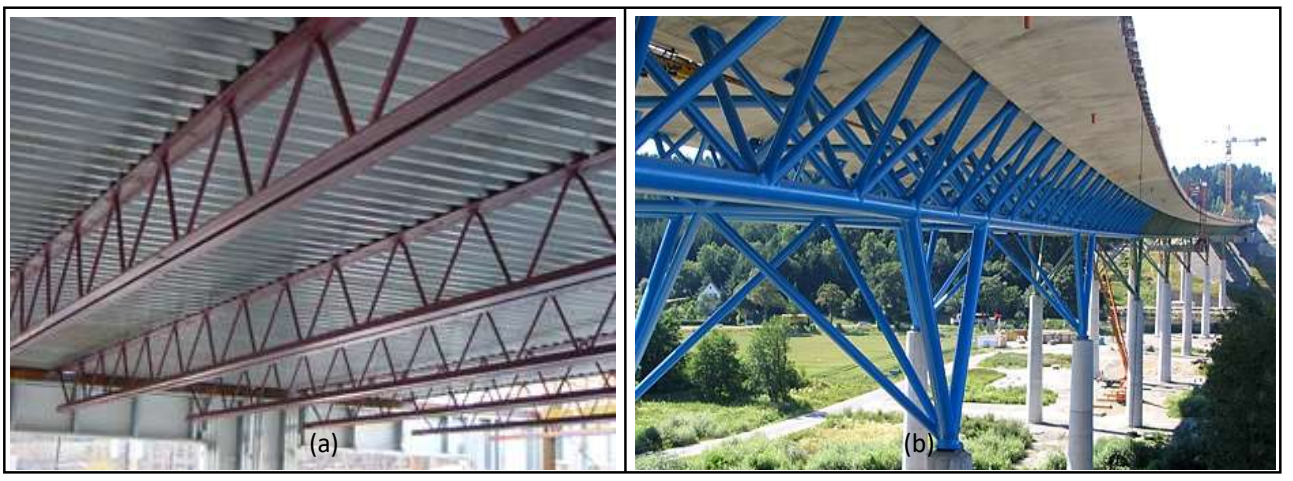

Fig. 1. Composite trusses in building floor (a) and bridge girders lacking upper truss chords (b).

In the case of a composite truss, the longitudinal forces are introduced into the concrete slab similarly only locally in the nodes, where the web members are connected to the compressed chord EN 1994-2 [2]. The finite element analyses can be used to investigate numerically this structural system behaviour, exploiting several computer procedures. Nowadays, different types of shear connectors are used. In this investigation, shear connection is developed using the welded headed studs. The proposed procedures are based on the results of recently completed experimental research. The outputs of this research are presented in the paper.

\section{Composite truss beam tests}

To analyse the global behaviour of steel-concrete composite trusses, experimental program was implemented [3]. Four similar steel-concrete composite truss beams of span $3.75 \mathrm{~m}$ were prepared. Steel truss components were made from the steel S235. Upper chord of the beam was prepared from $1 / 2$ IPE 160, bottom chord from two welded UPE 120 in box component. The web members at lateral parts consisted of square hollow section SHS 70x70x6.3 and the middle diagonals of the square hollow section SHS 40x40x3. Concrete slab of size $800 \times 100$ $\mathrm{mm}$ was made with demand on concrete class C25/30. Transversal and longitudinal reinforcement was formed from the bars $\phi 10$. Shear connection was provided by headed stud of diameter $10 \mathrm{~mm}$ and height $50 \mathrm{~mm}$ located only above the nodes as it shown in Figure 2.

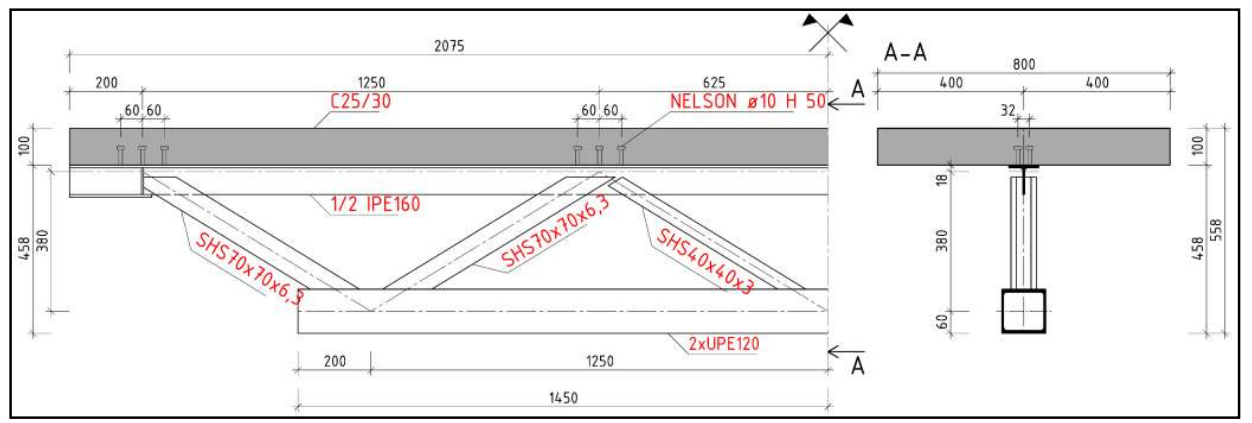

Fig. 2. Components of composite truss specimen.

Experimental testing using progressively static loading applied in the thirds of span above nodes is illustrated on the third truss specimen (Figure 3). Strains were recorded in both 
chords and web members of the girders as well as concrete slab by system of sixteen strain gauges.

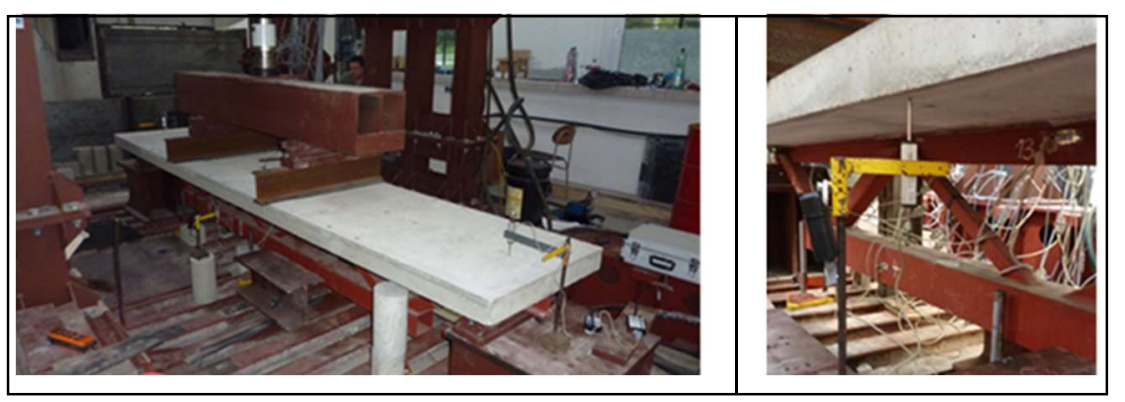

Fig. 3. Loading and general view on measurement system.

The details positions of the devices for strain registration in cross sections are labelled as T1 to T16. During the testing, the end slips of concrete slab have been measured using displacement sensors as P19 to P22. The deflection transducers were situated at the girders ends as well as in the middle P16 and the ones P14, P18 near the quarter part of span, as it shown in Figure 4. Data received from the strain gauge package were digitized and sent to the notebook. This computer was used to communicate with the measurement system for commands regarding data acquisition, downloading and display. Thus, reliable system already approved in the previous testing, reported in [4].

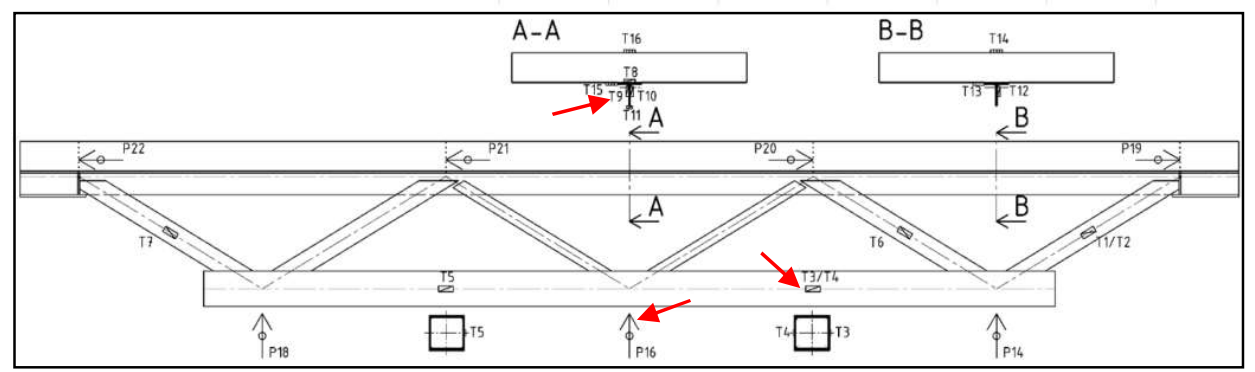

Fig. 4. Deflection, slip and stress sensors arrangement.

The recorded deflections have been initially developing proportionally till the loading level of $325 \mathrm{kN}$. This maximum value of elastic load carrying capacity is in appropriate correlation with the result of the analyses according to EN 1994-2 [2]. The whole truss deflections under supplementary loading have been growing slightly nonlinearly and produced the ultimate permanent vertical deflection of $33 \mathrm{~mm}$ at the end of test.

Even the stress distribution in strut sections has been initially rather uniform and progress proportionally. However, with increasing loading, the resulting stress patterns have proved different faster development. Especially the upper chord yielded rapidly in the mid-span sections due to combination of bending and compression as a result of significant beam deflections. Finally the chord failed by local instability. The experimental limit load carrying capacity of the specimen was $530 \mathrm{kN}$.

In the beginning, also longitudinal slips in shear connection have been unimportant along the entire composite beam span with a symmetrical distribution to the mid-span. The slip shapes progressively became more irregular and finally fully irreversible. The maximum slip at the truss end was $8.1 \mathrm{~mm}$ and at the opposite beam edge only $5.9 \mathrm{~mm}$. The limit state has been achieved at the load value under which the connectors in the support zone happening to fail by shearing, as it can be seen at Figure 5. In this stage, the connectors in span were only 
somewhat distorted by bending thanks to favourable loading. The behaviour already identified in the other investigation [5].

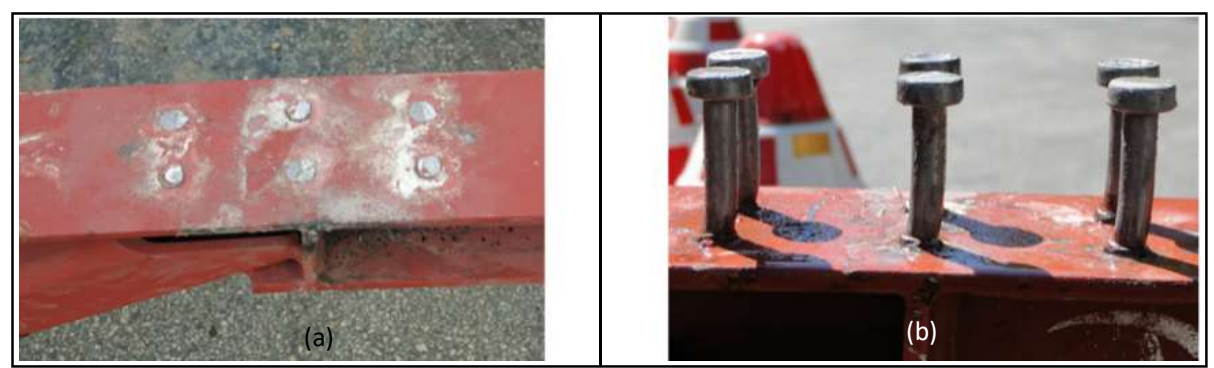

Fig. 5. Shear failure of connectors at the edge zone (a) and in less stressed interior span area (b).

\section{Numerical study of truss shear connection behaviour}

The finite element analyses can be used to investigate numerically shear connection of the truss structural system, exploiting several computer procedures. The software CAD of Scia system [10] was used to evaluate the structural behaviour of a reference composite truss, taken from the above experimental investigation. Serious considerations had to be given to proper representation of the geometric characteristics.

\subsection{Common composite truss widespread in building}

To simulate the actual composite action of the tested common truss with both chords, beside real shear headed studs connectors $\phi 10 / 50 \mathrm{~mm}$ used at the key positions shown in Figure 6, the others connection models were developed.

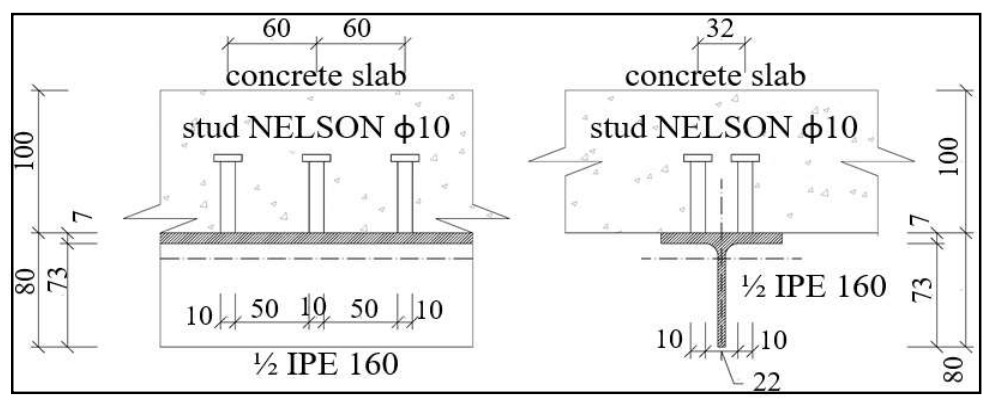

Fig. 6. Real steel connectors.

The alternative model 1 takes into account influence of surrounding concrete by tubeshaped envelope under stud head of $19 \mathrm{~mm}$ in diameter, as illustrated in Figure 7. Considering second moment of steel shank area $\mathrm{I}_{\mathrm{S}, \mathrm{St}}=\pi . \mathrm{D}_{\mathrm{S}, \mathrm{St}}{ }^{4} / 64=491 \mathrm{~mm}^{4}$, the concrete tube can contribute to the resulting sectional characteristic by the value $\mathrm{I}_{\mathrm{C}, \mathrm{C}}=5910 \mathrm{~mm}^{4}$. Resulting effective composite connector second moment of area would be $\mathrm{I}_{\mathrm{eff}}=1360 \mathrm{~mm}^{4}$. Introducing this modified sectional parameter in the computation model, the deflections might be more exactly theoretically reproduced, as illustrated by dot-dash line in Figure 11b. But in the case of normal stresses, the accuracy seems inferior, especially apparent in Figure 10. 


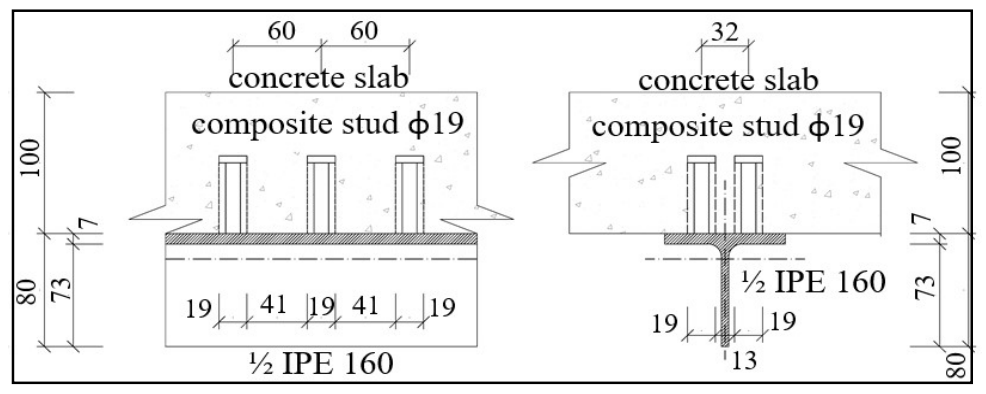

Fig. 7. Tube-shaped model 1 of composite studs.

For this reason, the next stud connector model 2 according to Figure 8 may consider slight larger concrete cylindrical stud cover entirely of $33 \mathrm{~mm}$ in diameter. The second moment of its area would increase at $\mathrm{I}_{\mathrm{C}, \mathrm{C}}=57700 \mathrm{~mm}^{4}$. Thus effective value of this parameter will be greater and equal to $\mathrm{I}_{\mathrm{eff}}=9010 \mathrm{~mm}^{4}$. From dash line in Figure 11, it is evident improved agreement in stress development, but inferior accordance of deflections progress.

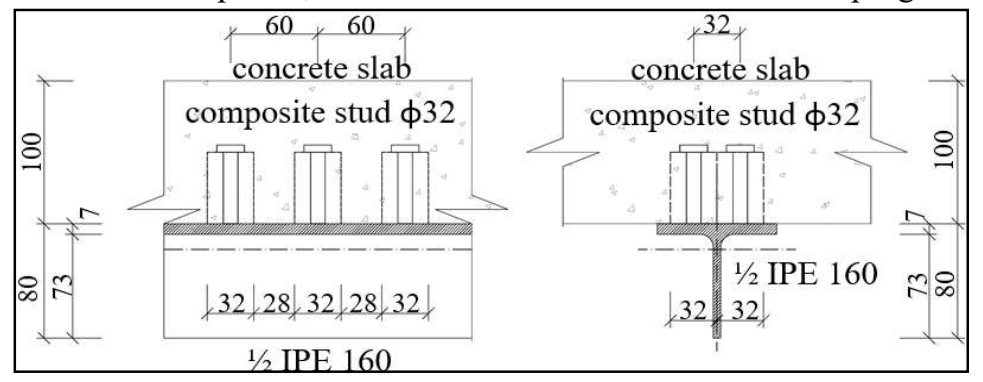

Fig. 8. Another cylinder-shaped model 2

The in-between shape model 3 might simulate composite stud as a tapered concrete cone, surrounding steel shank with its diameter of $20 \mathrm{~mm}$ at top and $80 \mathrm{~mm}$ in bottom base, as it is shown in Figure 9. Due to limit mutual pitch, a cone intersection usually can arrive. The approximation to the cylinder should be generally imposed using equality of volume of both connection bodies. In this example, the real cone-shaped connector volume is $V_{c}=91300$ $\mathrm{mm}^{3}$. The equivalent diameter of cylinder-shaped composite stud would be $50 \mathrm{~mm}$ with the second moment of area $\mathrm{I}_{\mathrm{C}, \mathrm{C}}=327000 \mathrm{~mm}^{4}$ and the effective value of this sectional characteristic $I_{\text {eff }}=48800 \mathrm{~mm}^{4}$. The dotted lines in Figure 10 indicate even stronger conformity of stress results.

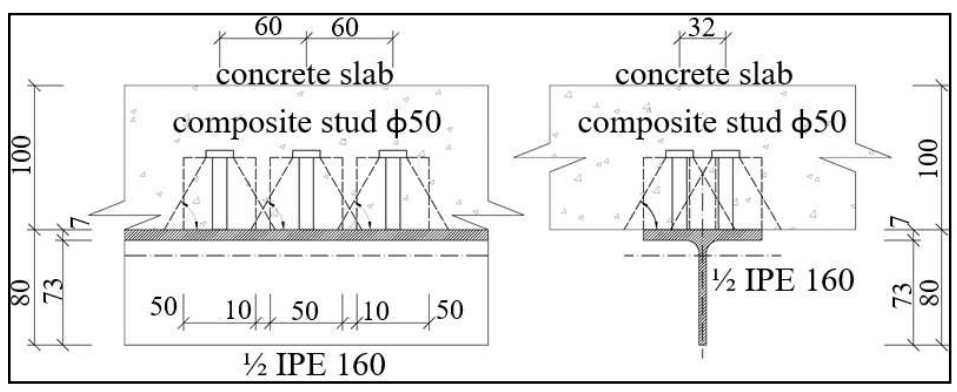

Fig. 9. Conic model 3 of composite studs.

Summary of experimental and numerical values of stresses in upper chord of tested truss sample as function of progressively increasing load is given in Figure 10. The progressive 
experimental stresses development in the lower chord represents similarly by lines in Figure 11a.

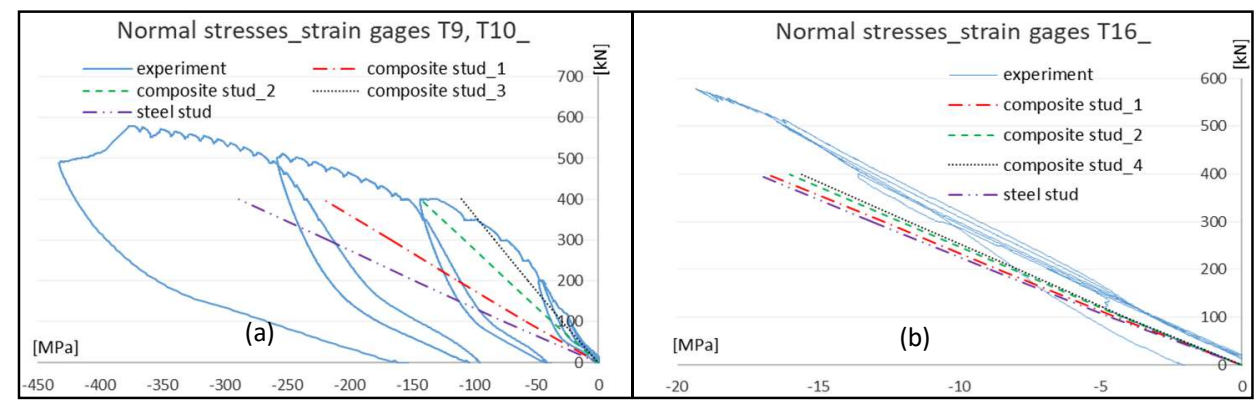

Fig. 10. Normal stresses in steel (a) and concrete parts of the upper chord (b).

But inversely, it is apparent a significant drop of accuracy between theoretical and experimental deflection values, demonstrated by the dotted line in Figure 11b. Therefore the tapered cone model 3 with top head equal to stud head diameter and lateral area extended down with slope of $60^{\circ}$ can be recommended for ultimate limit state verification.

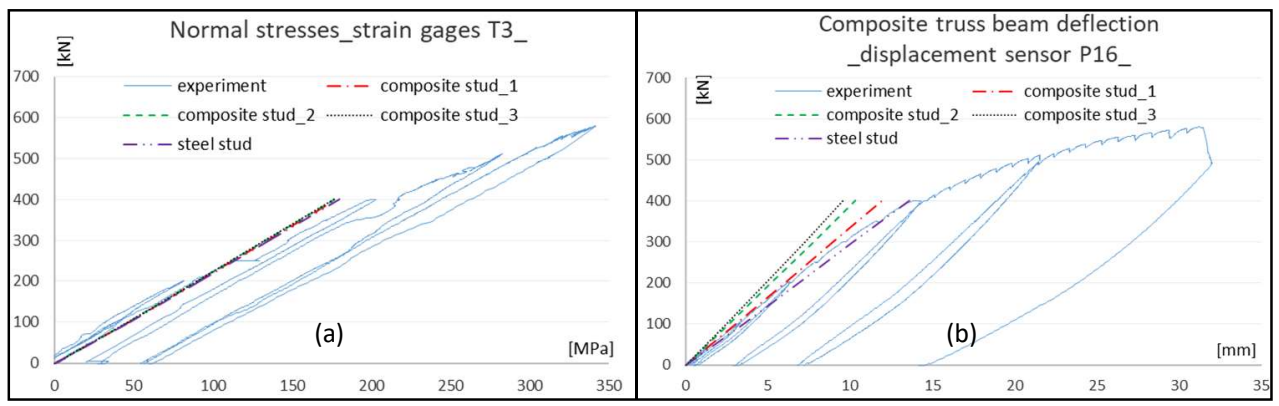

Fig.11. Stresses in the bottom chord (a), deflections registered by traducer P16 in the mid-span (b).

\subsection{Bridge composite truss form}

The most economic form of bridge truss consists of the diagonals with the optimum inclination about $45^{\circ}$ carrying shear, even without vertical members. The steel inferior tension chord and compression concrete upper deck should transmit bending moments. A common method of joining the panel members to a concrete upper deck is by means of short gusset plates at the joints where the members meet, as it can be seen in Figure 12.

At the critical locations, there is a shear in addition to direct loads and moment. It is evident that shearing connections should be checked in the joints to see whether their behaviour is within allowable limits. Determination of actual stresses is not simply possible because of load concentrations, warping of plate sections and local yielding. Thus, the other test on composite truss with discontinuous upper steel chord sections and different stress transmission was conducted to identify behaviour of this type of connections.

The size and shape of the tested sample is given in Figure 12. The sensors location for strains as well as deflections registration is slightly different in comparison to the preceding truss testing. 


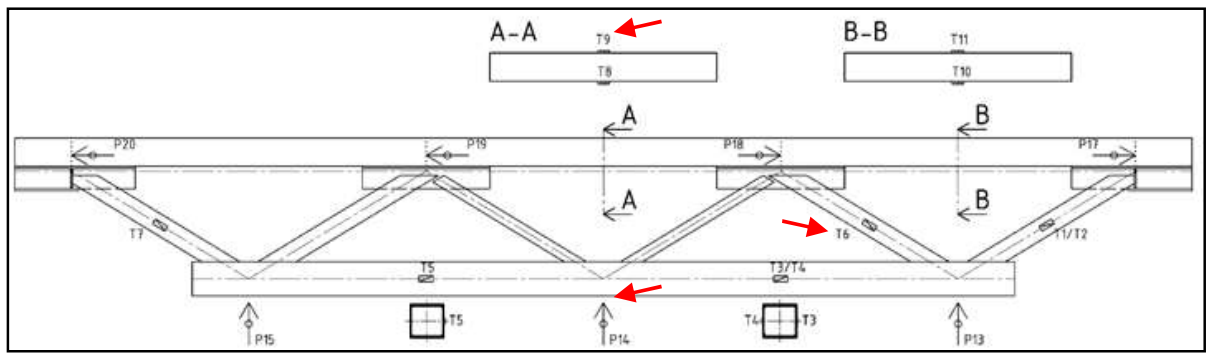

Fig. 12. The shape of composite truss with discontinuous upper chord with sensors locations.

The method considering model 3 of a stud, as the tapered concrete cone, yield stress values which more accurately represent actual experimental stresses. In Figure 13, there are characterized by dotted lines. This type of connector model considering concrete composite action could be applicable for stress calculation even of trusses with discontinuous upper chord.

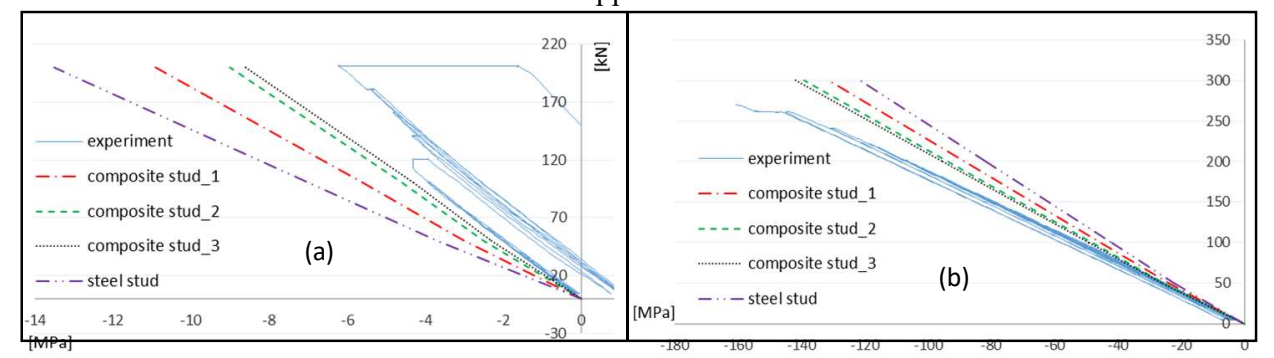

Fig. 13. Stresses in the sensors $T 9$ at the mid-span section of the upper chord (a) and diagonal T6 (b).

Effectiveness of concrete slab as an integral part of composite truss depending on shear connection seems to drop in serviceability limit state. In verification of composite truss deflections, it should be assumed that only a portion of surrounding concrete may work together with stud shear connector. As it can be seen in Figure 14, the cylinder-shaped model 2 provided deflection values close to the experimental results.

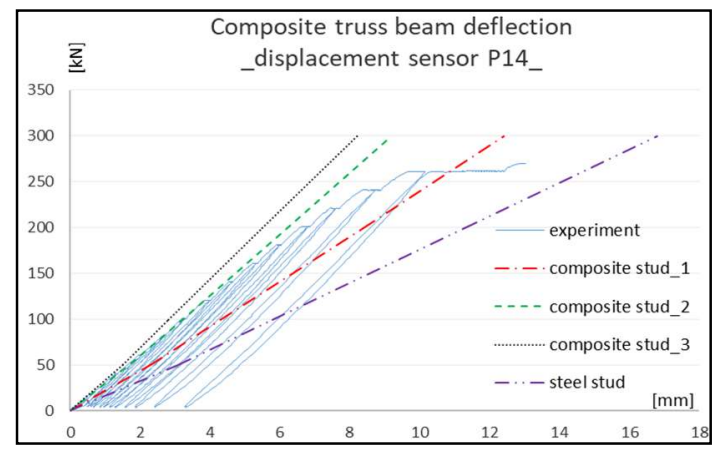

Fig. 14. Composite truss deflections registered by the deflection traducer P14 in the mid-span.

\section{Concluding remarks}

In the paper, the experimental and calculating procedures of the steel-concrete composite trusses with stud shear connectors were presented. The investigation of series was performed on the similar test composite truss specimens with continuous and broken steel upper chords. 
In the proposed procedure, the four different stud connectors models were developed and exanimated. They were additionally verified by the results of measurements. The comparison of experiment results and recommended theoretical curves confirm a good agreement in deflection development of the model 1 considering concrete tube-shaped envelope under stud head. However, model 3 simulating composite stud as a tapered concrete cone can provide higher accuracy in stresses.

Even in the case of composite truss with discontinuous upper cords supporting concrete deck only at joints, where the members meet. However the cylinder-shaped model 2 may be recommended for verification of deflections of trusses with broken upper chords. The calculation models can reflect more really trusses behaviour in comparison to the previous procedure in the paper [6]. Generally, the comparisons are in good agreement with the numerical result, if the extremely complex character of composite truss is considered.

\section{Acknowledgment}

The paper presents results of the research activities supported partly by the Slovak Cultural and Educational Grant Agency; grant No. 019ŽU-4/2016.

\section{References}

1. EN 1994-1-1, Eurocode 4, Design of composite steel and concrete structures, Part 1-1, General rules and rules for buildings, (2006)

2. EN 1994-2, Eurocode 4, Design of composite steel and concrete structures - Part 2: General rules and rules for bridges, (2005)

3. J.Bujňák, Z.Perkowski, Performance study of composite truss, Conference Proceedings of the 4th International Conference on Contemporary Achievements in Civil Engineering, Subotica, Serbia, p. 165-172, (2016)

4. J.Bujňák, A.Bouchaïr, Theoretical and experimental research on steel-concrete composite truss, Proceedings of the 37th IABSE Symposium, Madrid, pp. 478479,(2014)

5. J.Bujňák, K.Furtak, Connection slip in composite elements under quasi-long-term actions. Journal Pollack Periodica, Volume 9, p. 29-34,(2016)

6. P.Ďratná, J.Bujňák, A.Bouchaïr, Behavior of steel-concrete composite trusses. Journal Pollack Periodica, Volume 8,p. 23-28, (2016)

7. D.Lam, E.Lobody, Behaviour of Headed Stud Shear Connectors in Composite Beam. Journal of Structural Engineering. ASCE, p. 96 - 107, (2005)

8. J.Macháček, M.Čudejko, Composite steel and concrete trusses. Engineering Structures 33 (6), p. 3136 - 3142, (2011)

9. R.P. Johnson, Composite structures of steel and concrete. Volume 1. Beams, Columns, Frames, and applications in buildings. Crosby Lockwood Staples, London, (1975)

10. J.Bujňák, Composite steel and concrete structures. University of Žilina, p.213, (2017) 